\title{
Mitochondrial gene defects in patients with NIDDM
}

\author{
J.C.Alcolado ${ }^{1}$, A.Majid ${ }^{1}$, M. Brockington ${ }^{2}$, M. G.Sweeney ${ }^{2}$, R.Morgan ${ }^{1}$, A. Rees ${ }^{1}$, A. E.Harding ${ }^{2}$, A.H. Barnett ${ }^{3}$ \\ ${ }^{1}$ Department of Medicine, University Hospital of Wales, Cardiff, UK \\ ${ }^{2}$ Department of Clinical Neurology, Institute of Neurology, London, UK \\ ${ }^{3}$ Department of Medicine, University of Birmingham, Birmingham, UK
}

\begin{abstract}
Summary Non-insulin-dependent diabetes mellitus (NIDDM) has a strong genetic component and maternal factors have recently been implicated in disease inheritance. The mitochondrial myopathies are a group of diseases which often show maternal inheritance as a result of mtDNA defects; some patients have impaired glucose tolerance. Occasional families with maternally inherited diabetes and deafness associated with a deletion or point mutation of mtDNA have been reported. To assess the importance of mitochondrial gene defects in NIDDM, 150 unrelated diabetic subjects from Wales, UK and 68 unrelated patients with diabetes and at least one affected sibling from England, UK were studied. Southern blot analysis did not show any large mtDNA deletions or duplications. One patient had a mutation in the mitochondrial tRNA ${ }^{\text {leu(UUR) }}$ gene at bp 3243. This mutation is commonly associated with
\end{abstract}

the syndrome of mitochondrial encephalomyopathy, lactic acidosis and stroke like episodes (MELAS). Study of this patient and his siblings showed a distinct form of late-onset diabetes associated with nerve deafness but no clinical features of the MELAS syndrome. No diabetic subject was shown to have the mtDNA mutation at position 8344 (tRNA ${ }^{\text {lys }}$ ) which has previously been described in the syndrome of mitochondrial encephalomyopathy and red-ragged fibres (MERRF). The role of other mitochondrial gene defects in diabetes and the pathophysiological basis of glucose intolerance in patients with the MELAS mutation requires further elucidation. [Diabetologia (1994) 37: 372-376]

Key words Genetics, diabetes mellitus, mitochondria, maternal, deafness.
Genetic factors play an important role in the aetiology of NIDDM [1-4] and the chromosomal genome has been the focus of many studies in the search for causative mutations [5-9]. By contrast, mtDNA has not been studied systematically in diabetes. Human mtDNA is circular and consists of $16569 \mathrm{bp}$ of DNA which have been fully sequenced [10]. mtDNA is effectively exclusively maternally inherited and encodes 13

Received: 3 August 1993

and in revised form: 21 October 1993

Corresponding author: Dr. J.C. Alcolado, Department of Medicine, University Hospital of Wales, Heath Park, Cardiff CF4 4XN, Wales, UK

Abbreviations: mtDNA, mitochondrial DNA; tRNA, transfer RNA; NIDDM, non-insulin-dependent mellitus; bp, base pair; $\mathrm{PCR}$, polymerase chain reaction subunits of the respiratory chain and oxidative phosphorylation enzymes, 22 tRNAs and 2 ribosomal RNAs. Oxidative mitochondrial metabolism is of decisive importance in the regulation of insulin production in the pancreatic beta cell [11].

Studies suggest that mtDNA is of potential importance in the pathophysiology of NIDDM. Several authors including ourselves have reported a maternal effect in the transmission of the disease [12-14]. Although transmission is not exclusively maternal, the findings suggest that in a proportion of patients or families, maternal inheritance may be important. Whilst this observation may reflect the effects of intrauterine environment or imprinting [15], the influence of maternally inherited genetic elements such as mtDNA must be considered.

The mitochondrial myopathies are a group of diseases which result in variable ophthalmoplegia, ence- 
phalopathy and generalised muscle weakness [16]. Many are associated with defects of the mitochondrial genome (deletions, duplications or point mutations) [17-19]. Glucose intolerance or frank diabetes mellitus occurs in some subjects with mitochondrial myopathy [20-22]. Of particular interest is the recent report of a mtDNA deletion occurring in association with diabetes and deafness but no other neurological deficit in several members of a large family [23].

In addition, several groups have reported the presence of a mutation at position 3243 of mtDNA in families with NIDDM [24-27]. This mutation is characteristically associated with the syndrome of mitochondrial encephalomyopathy, lactic acidosis and strokelike episodes (MELAS) [28]. These families originally came to attention because they showed maternal inheritance of diabetes. Other workers have documented the 3243 bp mutation in diabetic subjects with MELAS and in their relatives who have diabetes but no clinically apparent neurological deficit $[29,30]$.

To assess the prevalence of mitochondrial gene defects in NIDDM, we studied 68 unrelated affected subjects with a strong family history of the disease and 20 of their affected siblings. In addition we studied 150 unrelated subjects with NIDDM ascertained without regard to family history. We searched for the presence of two previously described mtDNA mutations at $3243 \mathrm{bp}$ and 8344 bp in all subjects. A search for large mtDNA deletions and duplications was performed in the 68 subjects with affected siblings.

\section{Subjects and methods}

Index patients $(n=68)$ with NIDDM were identified from diabetic clinics at Addenbrooke's Hospital, Cambridge and St. Bartholomew's Hospital, London, UK; all had at least one affected sibling with NIDDM. All met World Health Organisation criteria for diabetes and were either non-insulin treated or had been controlled without insulin for at least 2 years and had no evidence of previous ketoacidosis. Blood $(10 \mathrm{ml})$ was collected from the probands and 20 available affected siblings ( 17 affected pairs, 3 affected triplets). Thus, the total number of subjects studied in this group was 88 (mean age $58 \pm 9.7$ years, BMI $25.3 \pm 6.3 \mathrm{~kg} / \mathrm{m}^{2}$ ). Control subjects $(n=32)$ with no family or personal history of diabetes (mean age $51 \pm 12.1$ years, BMI $23.6 \pm 4.2 \mathrm{~kg} / \mathrm{m}^{2}$ ) were also recruited at the same time and all samples underwent similar experimental and storage procedures.

Blood samples were also collected from a further $150 \mathrm{sub}-$ jects with NIDDM, who met the aforementioned criteria, living in the Cardiff area of Wales, UK (mean age $53.5 \pm 9.7$ years, BMI $28.8 \pm 5 \mathrm{~kg} / \mathrm{m}^{2}$ ). These patients were ascertained without regard to family history.

DNA was extracted from peripheral leucocytes as previously described in detail [31]. For the detection of mtDNA deletions or duplications, aliquots $(8 \mu \mathrm{g})$ of DNA from the group of diabetic patients with a positive family history were digested with PvuII and BamH1 according to the manufacturer's recommendations (BRL, Paisley, UK) and then run on $0.85 \%$ agarose gels at $55 \mathrm{~V}$ for $16 \mathrm{~h}$. Gels were Southern blotted onto Hybond (Amersham Int., Amersham, Bucks., UK) membranes and fixed by ultra- violet transillumination. Membranes were then hybridised to ${ }^{32}$ P-labelled linearised mtDNA probe. The mtDNA probe was prepared "in house" by the method of Hare et al. [32]. Autoradiography was performed with Fuji RX film at $-70^{\circ} \mathrm{C}$ for $24 \mathrm{~h}$ and a further film developed after another 7 days.

For detection of the 3243 bp mutation, aliquots of DNA $(0.5 \mu \mathrm{g})$ from all subjects were amplified using PCR using a forward primer (M1) corresponding to bp 3130-3149 of mtDNA (AGGACAAGAGAAATAAGGCC) and a reverse primer (M2) spanning bp 3558-3539 (TAGAAGAGCGATGTTGAGAG). Heat-stable Taq polymerase (Promega, Southampton, UK) was used together with the manufacturer's standard reaction buffer in a 30 cycle $\mathrm{PCR}$ reaction ( $30 \mathrm{~s}$ each at temperatures $55^{\circ} \mathrm{C}, 72^{\circ} \mathrm{C}$ and $92^{\circ} \mathrm{C}$ followed by a 10 -min final extension stage). PCR products were digested with 15 units of ApaI (BRL) for $1 \mathrm{~h}$ at $37^{\circ} \mathrm{C}$. Pairs of digested and undigested (to serve as control) samples were loaded onto $3.2 \%$ agarose gels and electrophoresed at $65 \mathrm{~V}$ for $2 \mathrm{~h}$ prior to visualisation of fragments by ultraviolet transillumination.

For the detection of the $8344 \mathrm{bp}$ mutation, aliquots of DNA $(0.5 \mu \mathrm{g})$ from all subjects were amplified using a modified forward primer (M3) corresponding to bp 8386-8336 of mtDNA (GTAGTATTTAGTTGGGGCATTTCACTGTAAAGCCGT GTTGG) and a reverse primer (M4) spanning bp 8278-8305 (CTACCCCCTCTAGAGCCCAC) using the same PCR conditions as for detection of the $3243 \mathrm{bp}$ mutation. The result was a product of $108 \mathrm{bp}$. In the presence of the $8344 \mathrm{bp}$ mutation, this product is cut by Bgl1 (Gibco, Paisley, UK) into fragments of $66 \mathrm{bp}$ and $42 \mathrm{bp}$ which may be separated by electrophoresis on $3.2 \%$ agarose gels for $1 \mathrm{~h}$ at $85 \mathrm{~V}$ [19].

Sample numbering in the experiments was designed so that it was not possible to distinguish control subjects from diabetic subjects nor to identify diabetic subjects which were related (i.e. siblings), until after the gels had been interpreted.

\section{Results}

\section{mtDNA analysis}

mtDNA is linearised by PvuII or BamH1 digestion, normally resulting in a single $16.5 \mathrm{~kb}$ band visualised by autoradiography after Southern blotting and labelling with ${ }^{32} \mathrm{P}$ mtDNA. Samples containing a population of mitochondria with a deletion will, in addition, contain an additional smaller fragment. Deletions or duplications of less than $2 \mathrm{~kb}$ may be poorly resolved by this technique but the method has been shown to detect mutant mtDNA species representing as little as $1 \%$ of total cellular mtDNA [33]. All of the 68 unrelated diabetic subjects with affected siblings showed a single band of appropriate size with both BamH1 and PvuII digestion, even after prolonged exposure of autoradiograms to augment the possibility of detecting additional bands. We could therefore not detect any mtDNA deletions or duplications in these subjects.

In the search for the mtDNA mutation at position $8344 \mathrm{bp}$, amplification of DNA samples with the primers M3 and M4 resulted in a product of $108 \mathrm{bp}$ in all diabetic and control subjects. Digestion with Bgl1 did not reveal any subjects with the mutation.

The $3243 \mathrm{bp}$ mutation was found in some of the mtDNA from peripheral blood of two diabetic sub- 


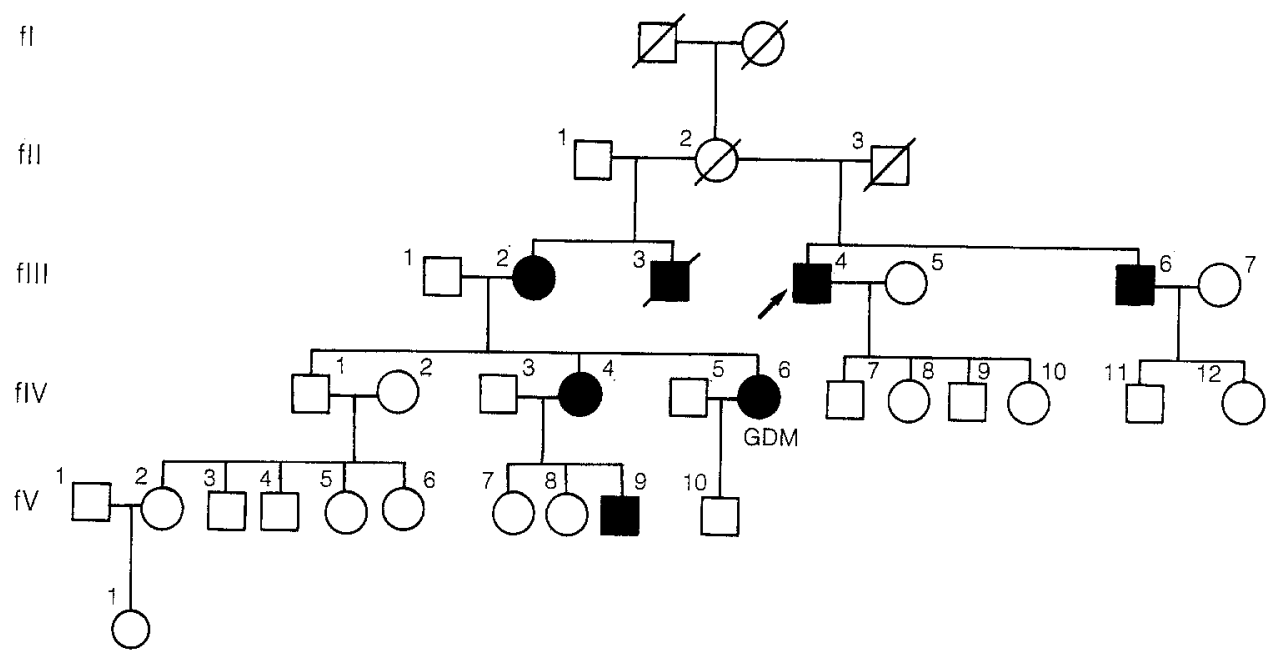

Fig.1. Pedigree of the family studied. Filled symbols represent subjects tested that had the 3243 bp mutation. Open symbol subjects were not tested. Each subject is identified by the generation in Roman numerals and by Arabic numbering from left to right. Subject IV.6 had gestational diabetes (GDM). The arrow represents the index case
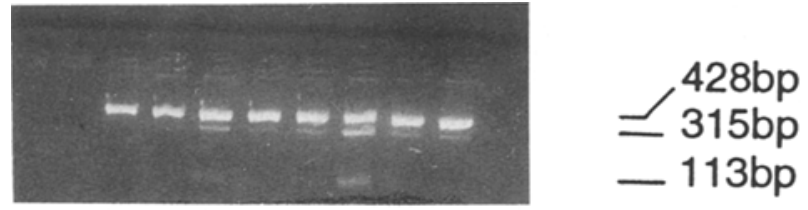

\section{8}

Fig. 2. PCR products after digestion with Apa1 and electrophoresis. The 3243 bp mtDNA mutation results in additional bands of $315 \mathrm{bp}$ and $113 \mathrm{bp}$; the $315 \mathrm{bp}$ band is better visualised but the intensity varies according to the amount of mutant mtDNA present in each subject. All patients possess the mutation although in lane 2 (subject III.6), the mutant fragment is not visible on this photograph; however, it was seen on direct inspection of the ethidium-stained gel. Each lane represents one subject. Lane 1 = negative control; Lane $2=$ III.6; Lane $3=$ III.4; Lane $4=$ III. $2 ;$ Lane $5=$ V.9; Lane $6=$ III.3; Lane $7=$ IV.6; Lane $8=\mathrm{IV} .4$

jects. When the sample numbers were uncoded, it was found that these two subjects were siblings. Other available members of this family were screened for the mutation and underwent a standard $75-\mathrm{g}$ oral glucose tolerance test.

\section{Family studies}

One of the diabetic subjects with the 3243 bp mutation had died between the time of blood sampling and the time of the above-mentioned experiments. His surviving sibling with the 3243 bp mutation was re-interviewed. He was 49 years old and had developed NIDDM 10 years earlier. His diabetes had been controlled with diet for less than 1 year and subsequently has been treated with oral hypoglycaemic agents until a few months before this study when insulin therapy was initiated because of deteriorating glycaemic control. The patient had noted gradual deterioration of hearing commencing approximately 5 years before the diag- nosis of diabetes. Within 10 years he had become profoundly deaf. A diagnosis of bilateral nerve deafness had been made but no cause found. He had been given bilateral hearing aids. After 7 years of the disease he was noted to have background diabetic retinopathy. No evidence of other diabetic complications or neurological disease was observed.

The pedigree of the patient is shown in Figure 1. His mother (II.2) died at the age of 41 with an unknown illness. One cause of death given on the death certificate is "bovine heart", a term denoting cardiomyopathy. No blood sugar records are available. She had been married twice and both of these partners are also deceased; a half-brother and half-sister of the proband both had NIDDM and impaired hearing. The half-brother (III.3) developed diabetes in his sixth decade and also had gradual hearing loss. This half-brother has since died (myocardial infarction) and represented the second positive sample in our original experiments. The halfsister (III.2) was 60 years old and had developed diabetes 9 years previously. She had noted gradual hearing loss during the preceding 5 years and currently uses a hearing aid in the right ear. Her diabetes had been controlled with diet alone for 7 years and oral hypoglcaemic agents during the last 2 years. No evidence of diabetic complications or neurological disease was observed. A 50-year-old full-brother (III.6) initially denied any history of hearing loss or diabetes. However, a pure-tone audiogram demonstrated bilateral high-pitch hearing loss and a 75-g oral glucose tolerance test fell within World Health Organisation criteria for NIDDM (fasting glucose $8.1 \mathrm{mmol} / \mathrm{l}$, 2-h glucose $13.4 \mathrm{mmol} / \mathrm{l}$ ).

Blood samples were obtained from these other siblings for mtDNA analysis. All siblings of our proband (generation III) were found to have the mtDNA mutation at position 3243 by PCR (Fig. 2). Subjects varied in the quantity of abnormal mtDNA that could be detected but there did not appear to be any relationship between the amount of amplified mutant and the severity of the diabetes. 
Two subjects in generation IV have been studied and both have inherited the mutant mtDNA (Fig. 2). Subject IV.6 is 29 years old and had gestational diabetes mellitus during her recent pregnancy. Subject IV.4 (38 years old) gave a 7-year history of increasing fatigue and muscle weakness, and occasional pain in the limbs. On examination there was variable resistance on testing muscle strength but power could be encouraged to normal. There were no other abnormalities. A muscle biopsy showed occasional ragged red fibres. A glucose tolerance test was abnormal (fasting $=5.1 \mathrm{mmol} / \mathrm{l}, \quad 30 \mathrm{~min}=7.3 \mathrm{mmol} / 1, \quad 60 \mathrm{~min}=8.5$ $\mathrm{mmol} / 1,90 \mathrm{~min}=8.1 \mathrm{mmol} / 1,120 \mathrm{~min}=7.9 \mathrm{mmol} / 1)$. The 16-year-old son of this subject also has the $3243 \mathrm{bp}$ mutation. He has no evidence of hearing impairment and a 75-g oral glucose tolerance test is within normal limits (fasting venous glucose $=5.5 \mathrm{mmol} / 1,30 \mathrm{~min}=$ $5.1 \mathrm{mmol} / 1,60 \mathrm{~min}=4.7 \mathrm{mmol} / 1,90 \mathrm{~min}=7.1 \mathrm{mmol} / 1$, $120 \mathrm{~min}=6.5 \mathrm{mmol} / \mathrm{l})$.

\section{Discussion}

This study has examined the prevalence of large mtDNA deletions and duplications and two previously described mtDNA point mutations in NIDDM. To screen a reasonably large number of patients, DNA from peripheral leucocytes was studied. In subjects carrying mitochondrial gene defects, cells may possess a variable number of mitochondria containing normal and/or abnormal mtDNA (heteroplasmy). This variation is due to unequal separation of the mitochondrial populations during mitosis. Muscle, which is a non-dividing tissue, tends to contain more mutant mtDNA than blood and is therefore the tissue of choice for investigation. Unfortunately, large numbers of muscle biopsy samples are not available in a prevalence study of this type. Pathogenic point mutations are detected in peripheral leucocytes in nearly all patients with neurological disease [19] suggesting this is a reasonable target to search for such defects. However in the mitochondrial myopathies associated with mtDNA deletions, the defect is rarely detected in blood as opposed to muscle. Nevertheless, in the diabetic family reported by Ballinger et al. [23], the large deletion was clearly demonstrated in peripheral leucocytes. However, the findings of Ballinger et al. [23] possibly represent a duplicated species of mtDNA as this is generally detectable in leucocyte DNA [34]. In diabetes the ideal tissue for study would be the pancreatic islet cell but this is difficult to obtain in man.

Family history of NIDDM is often incomplete because many relatives are never tested or die before they develop the disease. We therefore chose not to limit our search to subjects with a definite maternal history of the disease. However of the 68 subjects with affected siblings that were studied, 12 were aware of an affected mother, 3 of an affected father and 2 stated that both parents had diabetes. The remaining 49 subjects had affected siblings but were unaware of parental diabetes. We were vindicated in our approach since the mother of the siblings with the 3243 bp mutation in this study had died at an early age and her medical history was not known to her offspring. Thus had we limited our search to subjects with a clear maternal history, we would have missed our only positive family.

We identified a pathogenic mtDNA mutation, characteristically associated with the MELAS syndrome, in one of our 68 families. This mutation was reported originally in two kindreds with maternally transmitted diabetes $[24,25]$. In common with our family, nerve deafness was a predominant clinical feature cosegregating with diabetes. Although our family is relatively small, the striking phenotypic similarities, together with the fact that this mutation was not observed in more than 150 control subjects (i.e. those in the present study and those reviewed by Reardon et al. [25]), strongly supports the conclusion that the family found in the current study represents the same genetic syndrome.

In our family, one generation appears to have only diabetes and nerve deafness. One individual in the next generation had symptoms of fatigue and muscle weakness; however, her symptoms were out of proportion to the few red ragged fibres seen on muscle biopsy and it is possible that many of her symptoms are functional in origin. It is not known why the same mutation should be associated with a wide variety of phenotypes; modification by nuclear genes is a possibility. Alternatively, differential phenotypic expression may be a manifestation of heteroplasmy, with differential numbers of abnormal mitochondria in the neuromuscular and endocrine systems.

The early death of the mother in our family may suggest she suffered from an unusual disease process. The causes of death stated on her death certificate were "anaemia, hypertension and bovine heart". It is of interest that the $3243 \mathrm{bp}$ mutation has been associated with cardiomyopathy [25].

The three members of this family with diabetes and nerve deafness were all under the care of general physicians with an interest in diabetes. None had been suspected of having an unusual form of diabetes. Diabetes in two of the patients had been initially controlled with diet alone but with increasing age, oral hypoglycaemic agents and then insulin were required to maintain euglycaemia. None of the subjects were grossly overweight (BMI $21.6-24.8 \mathrm{~kg} / \mathrm{m}^{2}$ ) or had hypertension. Limited data in other pedigrees [26, 27] suggests that the 3243 bp mtDNA mutation may be associated with an insulin deficient type of diabetes. Detailed metabolic studies are currently being performed on available members of our pedigree.

From our study of over 200 subjects with NIDDM we conclude that the demonstration of the mtDNA mutations which we have investigated will not be a common occurence, at least in peripheral blood sam- 
ples. However, the results confirm that a particular form of late onset diabetes, associated with nerve deafness, is associated with the $3243 \mathrm{bp}$ mutation. The study of mitochondrial diseases continues to yield novel defects of mtDNA and further studies will be aimed at investigating the prevalence of these in NIDDM. Pathophysiological and molecular biological studies of mitochondrial function may significantly advance our understanding of this challenging metabolic disease.

Acknowledgements. JCA was the R.D. Lawrence Fellow of the British Diabetic Association.

\section{References}

1. Mohan V, Sharpe PS, Aber VR, Mather HM, Kohner EM (1986) Family histories in Asian and European non-insulin dependent diabetic patients. Practical Diabetes 3: 254-257

2. Newman B, Selby JV, King MC, Slemenda C, Fabsitz R, Friedman GD (1987) Concordance for type 2 (non-insulindependent) diabetes mellitus in male twins. Diabetologia 30: 763-768

3. Gottlieb MS, Root HF (1968) Diabetes mellitus in twins. Diabetes 17: 693-704

4. Barnett AH, Eff C, Leslie RDG, Pyke DA (1981) Diabetes in identical twins. A study of 200 pairs. Diabetologia 20:87-93

5. Cox NJ, Epstein PA, Spielman RS (1989) Linkage studies on NIDDM and the insulin and insulin receptor genes. Diabetes 38: 653-658

6. O'Rahilly S, Choi WH, Patel P, Turner RC, Flier JS, Moller DE (1991) Detection of mutations in insulin receptor gene in NIDDM patients by analysis of single stranded conformational polymorphisms. Diabetes 40: 777-782

7. Alcolado JC, Baroni MG, Li SR (1991) Association between a restriction fragment length polymorphism at the liver/islet cell (GLUT 2) glucose transporter gene locus and familial type 2 (non-insulin-dependent) diabetes mellitus. Diabetologia 34: 734-736

8. Bell GI, Xiang SK, Newman MV et al. (1991) Gene for noninsulin dependent diabetes mellitus (maturity onset diabetes of the young subtype) is linked to DNA polymorphism on chromosome 20 q. Proc Nat Acad Sci USA 88: 1484-1488

9. Vionnet N, Stoffel M, Takeda J et al. (1992) Nonsense mutation in the glucokinase gene causes early-onset non-insulindependent diabetes mellitus. Nature 356: 721-722

10. Wallace DC (1989) Report of the committee on human mitochondrial DNA. Cytogenet Cell Genet 51: 612-621

11. Sener A, Malaisse WJ (1987) Stimulation by D-glucose of mitochondrial events in islet-cells. Biochem J 246: 89-95

12. Dorner G, Mohnike A (1976) Further evidence for a predominantly maternal transmission of maturity-onset type diabetes. Endokrinologie 68: 121-124

13. Alcolado JC, Alcolado R (1991) Importance of maternal history of non-insulin dependent diabetic patients. BMJ 302: $1178-1180$

14. Bagriacik N, Ipbuker A, Ilkora H, Gorpe U, Ersan E, Ozyazar M (1991) Diabetes in Turkey: epidemiological characteristics 1959-1987. Diabetes 40[Suppl 1]: 434 A

15. Zemel S, Bartolomei MS, Tilghman SM (1992) Physical linkage of two mammalian imprinted genes, H19 and insulin-like growth factor 2. Nature Genetics 2: 61-65

16. Petty RKH, Harding AE, Morgan-Hughes JA (1986) The clinical features of mitochondrial myopathy. Brain 109: 915938
17. Holt IJ, Harding AE, Cooper JM et al. (1989) Mitochondrial myopathies: clinical and biochemical features of 30 patients with major deletions of muscle mitochondrial DNA. Ann Neurol 29: 699-708

18. Poulton J, Deadman ME, Gardiner RM (1989) Duplications of mitochondrial DNA in mitochondrial myopathy. Lancet I: 236-240

19. Hammans SR, Sweeney MG, Brockington M, MorganHughes JA, Harding AE (1991) Mitochondrial encephalopathies: molecular genetic diagnosis from blood samples. Lancet 337: 1311-1312

20. Lakin M, Locke S (1961) Progressive ocular myopathy with ovarian insufficiency and diabetes mellitus; report of a case. Diabetes 10: 228-231

21. Piccolo G, Aschei M, Ricordi A, Banfi P, Lo Curto F, Fratino $P$ (1989) Normal insulin receptors in mitochondrial myopathies with ophthalmoplegia. J Neurol Sci 94: 163-172

22. Mechler F, Fawcett PRW, Mastaglia FL, Hudgson P (1981) Mitochondrial myopathy: a study of clinically affected and asymptomatic members of a six-generation family. J Neurol Sci 50: 191-200

23. Ballinger SW, Shoffner JM, Hedaya EV et al. (1992) Maternally transmitted diabetes and deafness associated with a $10.4 \mathrm{~kb}$ mitochondrial DNA deletion. Nature Genetics 1:1115

24. Van den Ouweland JMW, Lemkes HHPJ, Ruitenbeek W et al. (1992) Mutation in mitochondrial tRNA.Leu ${ }^{(\mathrm{UUR})}$ gene in a large pedigree with maternally transmitted type II diabetes mellitus and deafness. Nature Genetics 1: 368-371

25. Reardon W, Ross RJM, Sweeney MG et al. (1992) Diabetes mellitus associated with a pathogenic point mutation in mitochondrial DNA. Lancet 340: 1376-1379

26. Katagiri H, Yamanouchi T, Oka Y (1993) Mitochondrial diabetes: clinical characterization of patients with mitochondrial tRNA ${ }^{\text {Ieu(UUR) }}$ gene mutation. Diabetes 42 [Suppl 1]: 109 A(Abstract)

27. Kadowaki T, Kadowaki H, Tobe K et al. (1993) A mutation in mitochondrial tRNA ${ }^{\text {Leu(UUR) }}$ gene in a pedigree with maternally transmitted insulin-deficient type of diabetes mellitus. Diabetes 42 [Suppl 1]: 95 A(Abstract)

28. Goto Y, Nonaka I, Horai S (1990) A mutation in the tRNAleu(UUR) gene associated with the MELAS subgroup of mitochondrial encephalomyopathies. Nature 1: 82-83

29. Sue CM, Holmes-Walker DJ, Morris JGL, Boyages SC, Crimmins DS, Byrne E (1993) Mitochondrial gene mutations and diabetes mellitus. Lancet 341:437-438(Letter)

30. Schulz JB, Klockgether T, Dichgans J, Seibel P, Reichmann H (1993) Mitochondrial gene mutations and diabetes mellitus. Lancet 341: 438-439(Letter)

31. Kunkel LM, Smith KD, Bayer SH, Boraonkor DS, Wathctel SS, Miller OJ (1977) Analysis of human Y chromosome specific reiterated DNA in chromosome variants. Proc Natl Acad Sci USA 74: 1245-1249

32. Hare JF, Cling E, Attardi G (1980) Isolation, sub-unit composition and site of synthesis of human cyt-c-oxidase. Biochemistry 19: 2023-2030

33. Larsson NG, Eiken HG, Bornan H, Holme E, Ordfors A, Tulinius MH (1992) Lack of transmission of deleted mtDNA from a woman with Kearns-Sayre syndrome to her child. Am J Hum Genet 50: 360-363

34. Poulton J, Deadman ME, Bindoff L, Morten K, Land J, Brown G (1993) Families of mtDNA re-arrangements can be detected in patients with mtDNA deletions: duplications may be a transient intermediate form. Hum Molec Genet 2: 23-30 